\title{
Trocas categoriais entre nomes e verbos na aquisição da escrita do Português Brasileiro por surdos
}

\author{
Category exchanges between names and verbs in the acquisition of the writing of \\ Brazilian Portuguese by deaf
}

\author{
Wasley de Jesus Santos* \\ Adriana Stella Cardoso Lessa-de-Oliveira**
}

\begin{abstract}
RESUMO: Neste artigo científico, dissertamos sobre o fenômeno linguístico da troca categorial entre nomes e verbos, cuja ocorrência foi identificada durante o processo de aquisição da escrita da interlíngua Português-Libras. Nossos objetivos principais são descrever e analisar, com base nos dados de nosso corpus e à luz da Gramática Gerativa, o processo de aquisição tardia das categorias nome e verbo em Português Brasileiro (PB), em modalidade escrita, tendo como objeto específico de investigação $\mathrm{o}$ fenômeno da troca categorial. As hipóteses iniciais desta pesquisa foram fundamentadas nos estudos de Kato (2005). Assumimos a hipótese de acesso indireto à GU na aquisição de segunda língua e hipotetizamos que os surdos realizam essa troca categorial por dois motivos: porque se guiam por aspectos sintáticos do $\mathrm{PB}$, ignorando aspectos morfológicos das categorias nome e verbo, e porque transferem para a escrita do PB a mesma indistinção categorial típica de sua L1 - a Libras. Essa pesquisa contou com 11

Abstract: In this scientific article, we discuss the linguistic phenomenon of the categorical exchange between names and verbs, whose occurrence was identified during the process of acquisition of interlanguage Portuguese-Libras. Our main objectives are to describe and analyze, based on the data of our corpus and in the light of Generative Grammar, how the late acquisition of the name and verb categories in the Brazilian Portuguese (BP) writing by the deaf has been occurring, having as a specific research object the phenomenon of categorial exchange. The initial hypotheses of this research were based on Kato (2005). We assume the hypothesis of the indirect access to UG in the acquisition of second language and hypothesize that the deaf perform the categorial exchange for two reasons: because they are guided by syntactic aspects of BP, ignoring morphological aspects of the name and verb categories, and because they transfer to writing of $\mathrm{BP}$ the same categorical indistinction typical of their L1 - Libras. This study had 11
\end{abstract}

\footnotetext{
* Mestre em Linguística. Professor do Instituto Federal de Educação, Ciência e Tecnologia Baiano - IF Baiano. wasleywa@hotmail.com

** Doutora em Linguística. Professora da Universidade Estadual do Sudoeste da Bahia - Uesb. adriana.lessa@gmail.com
} 


\begin{tabular}{ll}
\hline $\begin{array}{l}\text { sujeitos-informantes, todos surdos e } \\
\text { usuários da Libras como L1. A } \\
\text { metodologia de coleta de dados baseou-se } \\
\text { em produção de texto escrito e relatos de } \\
\text { experiência de vida gravados em vídeo. }\end{array}$ & $\begin{array}{l}\text { subjects-informants, all deaf users of } \\
\text { Libras as L1. The methodology of data } \\
\text { collection was based on the production of } \\
\text { written text and life experience reports } \\
\text { recorded on video. For the transcription } \\
\text { of the Libras data was used the SEL } \\
\text { utilizado o sistema SEL. }\end{array}$ \\
$\begin{array}{l}\text { PALAvarom. } \\
\text { linguagem. Interlíngua Português-Libras. } \\
\text { Troca categorial. }\end{array}$ & $\begin{array}{l}\text { KEYWORDS: Language Acquisition. } \\
\text { Portuguese-Libras } \\
\text { Category change. }\end{array}$ \\
\hline
\end{tabular}

\section{Introdução}

Há décadas, ciências conexas à Linguística vêm se interessando pela maneira como o ser humano adquire a linguagem e têm formulado propostas bastante interessantes que contribuem com a investigação do problema de aquisição da linguagem. Curiosamente, são bem recentes (e ainda parcas) as pesquisas linguísticas voltadas para a aquisição do Português Brasileiro (PB) escrito por pessoas com surdez, talvez porque essa demanda social minoritária só tenha começado a adentrar ao sistema público de ensino no Brasil nas últimas décadas do século XX, conforme nos explicam Gatti e Barreto (2009), o que consequentemente fez elucidar só recentemente a complexidade da questão.

Diante disso, este trabalho se localiza dentro dos estudos da Gramática Gerativa (CHOMSKY, 1972, 2005, 2006, 2009), tendo como base filosófica/perspectiva teórica o Inatismo, o qual afirma ter qualquer ser humano a predisposição natural para adquirir $^{1}$ uma ou mais línguas (CHOMSKY, 1972). Assim, buscamos, neste estudo, analisar o processo pelo qual sujeitos surdos, utentes de Libras, adquirem as categorias

\footnotetext{
${ }^{1}$ Assumimos o termo "aquisição" tanto para o processo referente à fala quanto para o referente à escrita, pois assumimos, com Kato (2005), que há acesso à GU também na aquisição da escrita, uma vez que: a) a escrita "é restrita pelos mesmos Princípios da GU, b) faz uso das mesmas categorias e funções (podem ser descritas pela mesma metalinguagem) e c) as opções gramaticais nelas presentes são previstas pelos Parâmetros da GU." (KATO, 2005, p. 140)
} 
nome e verbo do PB na modalidade escrita. Esta pesquisa se interessa pela maneira como os surdos se apropriam de alguns aspectos morfossintáticos dessas categorias lexicais, realizando ou não trocas entre elas, uma pela outra, considerando a morfossintaxe característica dessas categorias em $\mathrm{PB}$, isto é, apresentando ou não morfemas característicos de nomes e verbos ou adjetivos (em poucos casos) em posições sintáticas não correspondentes a tais categorias.

Mediante a caracterização da realização ou não da morfologia categorial convergente com a gramática do $\mathrm{PB}$, discutimos o processo de aquisição da modalidade escrita dessa língua por pessoas surdas com base na abordagem inatista de aquisição da linguagem. Consideramos, para tanto, a hipótese de Kato (2005) para a aquisição da escrita, conforme a qual o falante letrado é um bilíngue desigual que tem, em sua Língua-I, uma periferia marcada ${ }^{2}$ maior do que a dos não letrados. Ou seja, para a autora, a aquisição da escrita é um tipo de modalidade que toma a modalidade oral como base, caracterizando um processo de acesso indireto à Gramática Universal (GU). Acrescentamos a esse cenário o fato de o surdo estar adquirindo a modalidade escrita de uma língua cuja modalidade falada não é acessível a ele, ou o é indiretamente.

Assim sendo, o problema aqui investigado pode ser descrito como a verificação de trocas da morfologia categorial específica das categorias nome e verbo na produção escrita de pessoas surdas adquirindo o Português escrito. Vale ressaltar que é muito comum observar-se tais trocas categoriais em produções escritas de estudantes surdos, mesmo com anos avançados de escolarização.

\footnotetext{
${ }^{2}$ Kato (2005) propõe a hipótese de que, embora haja algumas semelhanças, a gramática da língua escrita é como uma segunda língua, pois o aprendiz chega à escola com uma gramática nuclear, a gramática da fala, e aprende a modalidade escrita na periferia marcada, que se constitui basicamente de regras estilísticas selecionadas arbitrariamente de gramáticas passadas ou emprestadas da gramática portuguesa. Nessa periferia marcada, o falante acessa a língua materna (L1) para a aquisição da escrita. Conferir Kato (2005, p. 132).
} 
A fim de explicar o fenômeno que constitui o problema abordado por nosso estudo, assumimos a hipótese de acesso indireto à GU, de acordo com a qual "o aprendiz de L2 é capaz de acessar a GU somente por meio do conhecimento da L1 armazenado na mente, ou seja, aquelas partes da GU que haviam sido ativadas na L1 podem ser utilizadas novamente, mas outras partes não estariam acessíveis." ${ }^{3}$ (MARCINIUK, 2007, p. 20). Assim, estamos assumindo a hipótese de interferência da primeira língua (L1) na aquisição da segunda língua (L2) devido ao acesso indireto à GU. No caso de nossa investigação, a L1 é a Libras (Língua Brasileira de Sinais) e a L2 o Português Brasileiro.

A assunção de tal hipótese nos leva a adotar uma metodologia de análise comparativa entre a estrutura gramatical relativa às categorias nome e verbo na Libras falada ${ }^{4}$ por nossos sujeitos-informantes e no Português escrito produzido por tais sujeitos. Assim, ainda que o foco de nossa investigação seja a produção escrita do Português por indivíduos surdos em processo de aquisição do PB escrito como L2, nesta investigação, tornou-se imprescindível a utilização também de dados da Libras.

Para fundamentar a comparação entre as duas línguas, partimos dos estudos gerativistas para descrição da estrutura morfossintática das categorias nome e verbo em Português e de estudos a respeito das características morfossintáticas dessas categorias em Libras (FELIPE, 2006; PIZZIO, 2011; CHAIBUE, 2013; LAVRAS, 2019).

Lançamos mão, neste estudo, também do conceito de interlíngua (IL) de Selinker ${ }^{5}$, que explica a natureza da produção linguística que ocorre nos vários estágios de aquisição de L2. Assim, no caso de nossa investigação, consideramos a

\footnotetext{
${ }^{3} \mathrm{~L} 1=$ primeira língua ou língua nativa; L2= segunda língua ou língua não nativa.

4 Por considerar que há modalidade falada e modalidade escrita tanto em línguas orais como em línguas sinalizadas, assumimos os termos 'fala', 'falante' e 'modalidade falada' também para as línguas de sinais.

5 "O termo Interlanguage (interlíngua) foi criado e aplicado pela primeira vez por SELINKER (1972) e denomina uma 'língua intermediária' desenvolvida pelo aluno quando do aprendizado da língua, ou seja, um sistema de transição entre elementos da língua-alvo já adquiridos e a língua-alvo final propriamente dita." (SPINASSÉ, 2006, p. 346)
} 
confluência entre as estruturas das duas línguas envolvidas no processo de aquisição de L2 - o Português, como língua-alvo, e a Libras, como língua nativa. Assumimos que essa confluência se reflete significativamente no processo de aquisição, resultando em estágios de interlíngua que denominamos no geral como interlíngua Português-Libras. Consideramos também que os surdos se submetem à aquisição de uma língua cujo canal perceptual é oroauditivo, distinto totalmente de sua primeira língua, a Libras, que utiliza o canal de percepção gesto-espaço-visual. Dessa maneira, o problema investigado neste estudo se delineia como um questionamento a respeito da ocorrência sem distinção morfológica das categoriais lexicais (nome e verbo) e do quanto as diferenças entre a morfologia categorial da Libras, língua nativa, e do PB, língua-alvo, se fazem presentes no processo de aquisição da modalidade escrita do PB por surdos, provocando características peculiares a uma possível interlíngua.

Como tentativa de resposta ao problema acima explicitado, foco de nosso estudo, e partindo da discussão de Kato (2005), assumimos a hipótese de acesso indireto à GU. Com base nessas ideias, levantamos abaixo as hipóteses (I) e (II) neste trabalho:

(I) Por se tratar de um processo de aquisição de L2 e em modalidade escrita, o surdo toma como base sua L1, a Libras, registrando-se, em sua produção escrita do $\mathrm{PB}$, grande volume de indistinção de marca morfológica categorial, devido à ausência morfofonológica de tais marcas nas categorias nome e verbo em Libras.

(II) $\mathrm{Na}$ interlíngua Português-Libras, os surdos se pautam principalmente em estratégias de natureza sintática, ignorando, em estágios iniciais, na maior parte dos casos, os aspectos morfológicos peculiares a categorias gramaticais em PB.

Neste trabalho, portanto, nosso problema gira em torno de questões relativas à aquisição de linguagem, especificamente a aquisição dos traços morfológicos das categorias nome e verbo na modalidade escrita do PB por surdos jovens usuários de Libras e com alguma experiência escolar com a escrita de sua L2. A partir disso, 
investigamos de que maneira se caracteriza a interlíngua que surge no momento da aquisição dessas duas categoriais lexicais mediante a estrutura argumental ${ }^{6}$, na escrita da L2, como resultado da interferência mesclada da L1 e da própria L2. Pontuamos, então, que esta investigação seja relevante para os Estudos Surdos e especificamente para a área de Aquisição da Linguagem, pois colabora com o avanço dos trabalhos teóricos atinentes à aquisição do PB como segunda língua por pessoas surdas, além de servir de base para a elaboração de materiais didático-pedagógicos adequados para o ensino da escrita dessa mesma língua como L2.

Em suma, como mencionamos, assumimos, neste estudo, a hipótese de acesso indireto à $\mathrm{GU}$, uma vez que o arcabouço linguístico mental também é utilizado pelo surdo no momento da aquisição da escrita, levando em consideração os conhecimentos linguísticos que ele tem de sua L1. Isso configurará a interlíngua que surge como resultado da confluência entre a L1 e a L2. ELevantamos hipóteses que abarcam a ideia de que o processo de aquisição do PB escrito por surdos falantes de Libras se pauta em estratégias de natureza sintática, por isso os surdos ignoram, na maior parte dos casos, aspectos morfológicos peculiares a categorias gramaticais do Português.

\section{As categorias nome e verbo em Português e em Libras}

Aspectos morfofonológicos e sintáticos são tomados como critério de distinção entre as categorias nomes e verbos em Português. Os traços categorizadores do verbo definem tanto as flexões morfofonológicas que marcam as propriedades de certos traços, como pessoa, número, tempo e aspecto, quanto as relações formais definidoras da posição sintática central do verbo no segmento oracional, que, em Português, estabelece a concordância entre verbo e sujeito. Já os nomes, únicos a terem a

\footnotetext{
${ }^{6}$ Em Gramática Gerativa, trata-se de uma estrutura sintática composta por um núcleo lexical (um item lexical, que possui conteúdo semântico), que seleciona argumentos internos e externos, atribuindo-lhes papéis temáticos (ou semânticos).
} 
prerrogativa de ser argumento $^{7}$ na estrutura oracional (e alguns advérbios em certos contextos), apresentam, em Português, flexões morfológicas específicas apenas para o traço de número, uma vez que grau e gênero ficam fora dessa lista, conforme Câmara Jr. (2011) e Villalva (2003), respectivamente.

Diferentemente do explicitado em Português, os nomes e os verbos em Libras não apresentam distinção morfológica entre essas categorias. Ainda não há consenso sobre isso, mas já há alguns trabalhos que chegaram a resultados que indicam a não existência de distinção morfológica entre as categorias gramaticais na Libras (FELIPE, 2006; PIZZIO, 2011; CHAIBUE, 2013; LAVRAS, 2019), ou seja, exatamente o mesmo sinal, sem nenhuma alteração morfológica, pode ocorrer como nome ou como verbo. De acordo com resultados obtidos por Lavras (2019) em pesquisa experimental, a inexistência de padrões de variação na realização de nomes e verbos localizada nos grupos de sujeitos-informantes testados por ela revelam uma indistinção, de forma generalizada, entre essas categorias em Libras. Assim, a autora assume que a categorização de nomes e verbos em Libras se dá de forma estrutural, ou seja, é definida dentro do contexto sintático.

\section{Procedimentos metodológicos}

Os procedimentos metodológicos adotados para esta pesquisa envolvem a coleta de dados em Libras e em PB escrito (ou interlíngua Português-Libras). Os dados de produção escrita em PB são o alvo de nossa investigação, e os dados em Libras foram coletados para servir de base à comparação entre as duas línguas, comparação essa fundamental à nossa proposta de análise ${ }^{8}$. Optamos por metodologia do tipo

\footnotetext{
7 Termos selecionados pelo predicador na estrutura argumental.

8 Optamos por coletar dados da Libras produzidos pelos mesmos informantes que produziram os dados escritos do PB, em vez de lançar mão de dados apresentados em outras pesquisas, porque consideramos este um procedimento mais pertinente a uma comparação que tem como objetivo observar a interferência da L1 de certo indivíduo na L2 que ele está adquirindo.
} 
naturalístico para a montagem do corpus, tanto na coleta de dados em Libras como na coleta de dados da interlíngua. Tal método se constituiu como coleta de amostras de produções linguísticas realizadas sem controle da situação de produção pelo pesquisador. Consideramos, com base em André (1995), que esse método naturalístico de coleta, que proporciona observação mais espontânea do fenômeno da troca categorial, se adequou bem às necessidades do nosso estudo, uma vez que lidávamos com fenômeno abundante na interlíngua, já observado aprioristicamente, e, no caso dos dados em Libras, a simples coleta de amostras daria conta da captura das categorias nomes e verbos sempre presentes em sentenças de qualquer língua.

Assim, o corpus desta investigação linguística foi constituído em ambiente escolar no ano de 2016, a partir de dados fornecidos com auxílio de tradutor-intérprete de Libras, por um grupo de 11 (onze) surdos jovens, de ambos os sexos, residentes no município de Vitória da Conquista, no sudoeste da Bahia, sendo todos usuários de Libras como língua nativa, não oralizados e com mais de cinco anos de experiência escolar em contato com a escrita do PB. Consideramos aqui a Libras como língua materna porque os surdos entrevistados não usaram outra língua antes da aquisição propriamente dita da Libras; assumimos, assim, que a Libras é, para eles, sua primeira língua.

Como veremos nos dados da pesquisa ${ }^{9}$, as amostras escritas apresentam características de uma interlíngua, e não do Português propriamente dito, isto é, apresentam-se como um sistema linguístico intermediário entre a Libras e o Português, devido às circunstâncias de aquisição que envolvem os surdos. Nas palavras de Santana (2007, p. 43):

\footnotetext{
${ }^{9}$ Por questão de concisão, apresentaremos neste artigo os dados, e respectiva análise, de apenas um dos sujeitos-informantes da pesquisa. Entretanto, com o intuito de demonstrarmos a amplitude do fenômeno pesquisado, apresentaremos os resultados sintetizados dos 11 sujeitos-informantes da pesquisa.
} 
devemos considerar que, nesse processo de aquisição, é possível que os surdos se comportem, pelo menos num primeiro estágio, como se estivessem adquirindo a modalidade escrita de sua L1. Como a L1 desses indivíduos é uma língua de sinais, a Libras (no caso da maioria dos brasileiros surdos), o resultado desse processo de aquisição da escrita de uma L2 oral, o Português, sem passar pela modalidade falada dessa língua, será uma interlíngua, com as marcas da Libras e do Português.

Isso pode ser percebido, entre vários outros indícios, porque são produções que não apresentam uma segmentação segura das sentenças através de sinais de pontuação e/ou por estruturas sentenciais claramente definidas, como vemos nos dados em (1), (2) e (3) abaixo.

(1) I futuro Saudade legal esnobar estuda não quero escola| (SI1 $\left.{ }^{10}\right)$ 'Sentirei Saudade. É legal, não esnobo o estudo, quero estudar.'

(2) I Eu dizer gostou estudando bom é muito I (SI3) 'Eu digo que gostei do estudo (ou de estudar). É muito bom'.

(3) I Dia escola tem aprender Libras ensino I (SI7) 'No dia da escola, tinha aprendizagem, ensinavam Libras', ou 'No dia da escola, tinha aprendizagem, ensino de Libras.'

Ao observarmos os dados à primeira vista, identificamos, na grande maioria dos textos, ausência de elementos de pontuação e o uso inadequado da letra maiúscula, o que tornou a identificação do início e do final das sentenças nos textos bastante difícil. Então, como a delimitação das sentenças é primordial neste tipo de investigação linguística, pois se faz necessária a identificação da estrutura sintática de cada sentença, e tendo em vista que os dados fornecidos pelos sujeitos-informantes no corpus da pesquisa por si sós não fornecem todos os recursos gráficos de identificação

\footnotetext{
10 SI, que aparece enumerado ao longo do texto, refere-se a Sujeito-Informante.
} 
das sentenças de que precisávamos, realizamos transcrição da interlíngua para o Português. ${ }^{11}$

Na etapa da análise dos dados, tomamos os dados em Libras gravados em vídeo para transcrevê-los, quando necessário, utilizando o sistema de escrita para língua de sinais SEL. ${ }^{12}$ A transcrição para a SEL é relevante nesta etapa da metodologia porque nos possibilita acessar, de forma o mais fiel possível, a articulação do segmento sentencial (e dos sinais) realizado em Libras, compreendendo sua estrutura interna e visualizando, ao mesmo tempo, a hierarquia de seus segmentos. ${ }^{13}$

É interessante ressaltarmos que a produção textual escrita de pessoas surdas, sobretudo a daquelas nascidas surdas, não oralizadas e que têm a Libras como L1, é quase sempre marcada por características que tornam o texto às vezes truncado, de

11 No trabalho de transcrição da interlíngua (encontrada nas produções escritas dos sujeitosinformantes) para o Português, utilizamos dois critérios, adotados por Sandes-da-Silva (2016), para ajudar na delimitação das sentenças e no trabalho de transcrição da interlíngua. A autora utiliza os seguintes critérios na ordem em que se apresentam: I- Interpretar e segmentar a sentença com base em tema(s) geral(is) do texto; II- Inserir o mínimo possível de itens para obtenção da gramaticalidade da sentença conforme o PB (SANDES-DA-SILVA, 2016, p. 49).

${ }^{12} \mathrm{O}$ acesso às regras de funcionamento da escrita SEL é amplo e fácil por meio do endereço: http://sellibras.blogspot.com/.

13 Optamos por utilizar a escrita SEL na transcrição dos dados em Libras por alguns motivos importantes: esse sistema de escrita já tem sido utilizado por alguns pesquisadores no país e a transcrição em SEL torna os dados em Libras acessíveis a esses pesquisadores e outros que venham a conhecer o sistema; a escrita SEL é um sistema que dá conta da representação da forma articulatória do sinal com exatidão e eficiência quanto à sua decodificação, dando acesso a informações de aspectos linguísticos presentes nos dados, fundamentais ao trabalho de pesquisa; além disso, consideramos necessário evitar sérios problemas ocasionados por utilização tão somente de glosas (sinais escritos por sistema de escrita de língua oral) na transcrição de dados de línguas de sinais. Segundo Almeida (2013), o maior problema da transcrição de sinais apenas por glosas está no fato de o pesquisador acabar por analisar "dados" que não refletem a língua de sinais, mas características gramaticais da língua oral utilizada nas glosas, uma vez que a estrutura gramatical desses dados não pode ser a da língua de sinais pesquisada. Para McCleary e Viotti (2007), a transcrição de dados de línguas de sinais por glosas apresenta fortes inconvenientes, pois esses autores acham precipitado o uso de indicações com valor gramatical para marcações não manuais e acham que deveria ser evitada a desvinculação do nome do sinal (sua glosa) da descrição de sua forma. Também a literatura internacional tem apontando as limitações dos procedimentos de transcrições de línguas de sinais tão somente por glosas, que vêm sendo utilizados comumente, e confirma a necessidade de as línguas sinalizadas serem estudadas por meio de corpora que realmente represente a língua produzida por sinalizadores fluentes (LIDDELL, 2003). 
difícil compreensão, com base no que afirmam Sandes-da-Silva (2016), Salles et. al. (2007) e Brochado (2006). Para essas autoras, isso talvez seja justificado, entre vários outros aspectos, pela ausência de elementos de coesão, pelas falhas na estrutura argumental, na seleção dos papeis temáticos e em aspectos gramaticais, como flexão de nomes, concordância verbal etc., conforme o que ficará explícito na análise dos dados.

A seguir, para ilustrarmos o que acabamos de descrever, apresentamos o texto de um sujeito-informante seguido da segmentação do texto e de sua reescrita, com base na gramaticalidade do PB.

Quadro 1 - Texto 1 - Transcrição do texto original do sujeito-informante 1.

Passado ano 2008 estuda tem vida surdo sala muito mais história bom gosto Libras ensino crescer sempre de língua de sinais Português importante por um pouco pessoa tem desejo acerca se precisa para tudo bem escota perdeu triste problema normal calma que fala aviso ajuda pode qualquer futuro Saudade legal esnobar estuda não quero escola desculpa culpa errado ano 2010 estuda todos sala surdos muitos escreito pelos deste

Fonte: Corpus da pesquisa ${ }^{14}$.

Quadro 2 - Texto 1 - Versão em Português do texto do sujeito-informante 1.

No ano de 2008, eu estudei. Houve, na sala de surdos, muito mais histórias. É bom, eu gosto. O ensino de Libras cresce sempre, o de língua de sinais e o Português são importantes. Poucas pessoas têm vontade de saber acerca disso, mas, se precisamos disso para tudo, é bom. Perdi na escola, fiquei triste, problema comum. Calma, que falo, informo e qualquer um pode ajudar. Sentirei saudade. É legal, não esnobo o estudo, quero estudar. Desculpa, foi

\footnotetext{
14 Grifo nosso.
} 
minha culpa se errei. No ano de 2010, todos estudavam na sala de surdos, mas ela era muito estreita para eles todos.

Fonte: Corpus da pesquisa.

\section{Descrição e análise dos dados}

O texto do sujeito-informante 1, apresentado no Quadro 1, caracteriza-se por sentenças longas e truncadas. Não há, como vemos no texto acima transcrito, nenhum elemento gráfico de pontuação, dificultando, por conseguinte, a delimitação das sentenças. $\mathrm{O}$ texto versa sobre a experiência passada do informante na convivência com outros surdos e sobre sua reprovação escolar, como se pode verificar, no Quadro 1, no trecho "escota perdeu triste problema normal", que traduzimos, no Quadro 2, como "Perdi na escola, fiquei triste, problema comum."

Como, de acordo com uma de nossas hipóteses, na interlíngua PortuguêsLibras, os surdos se pautam principalmente em estratégias de natureza sintática, ignorando, em fases iniciais, na maior parte dos casos, os aspectos morfológicos peculiares a categorias gramaticais em PB, valemo-nos, assim, da discussão teórica de Mattos (2000) e Kato (2005) acerca do acesso indireto à GU para analisarmos o fenômeno das trocas de categorias verificado no corpus, considerando a possibilidade do reflexo da estrutura gramatical da L1 na L2.

Na proposta teórica dessa segunda autora, na perspectiva do acesso indireto à GU, para os inatistas, os adquirentes de uma segunda língua têm acesso aos parâmetros da GU operacionalizados por meio de sua L1. Comenta Kato (2005, p. 141) que

a aquisição de L2 pode se dar por imersão, isto é, por exposição apenas a dados positivos, ou através de instrução, isto é, através de dados ordenados e negativos. A aquisição de L2, por imersão ambiental, e da escrita, via imersão em leitura, certamente apresentarão mais 
semelhanças com a aquisição de L1, essencialmente com base em dados positivos.

Discutindo a questão, Mattos (2000), ao abordar o problema de aquisição de segunda língua, explica que, segundo hipótese de White (1989, p. 37), “o aprendiz de uma segunda língua também enfrenta o problema de extrair sentido de dados linguísticos, de produzir um sistema que explique tais dados e que lhe permita compreender e produzir estruturas na L2" (MATTOS, 2000, p. 56).

Portanto, nossas hipóteses são favorecidas tanto pela ideia de que a aquisição é "parcialmente regulada pela GU e parcialmente por estratégias gerais de aprendizagem" (MATTOS, 2000, p. 58) quanto pela ideia de que o acesso à GU, conforme Kato (2005, p. 132), “é indireto, via a primeira gramática - a da língua falada", no caso da aquisição da escrita. Baseados nessa discussão teórica é que advogamos a interferência da Libras na escrita do Português como a principal motivadora do fenômeno da indistinção categorial que acontece na interlíngua, como veremos detalhadamente abaixo nas observações de ocorrência desse fenômeno nos dados de nosso corpus.

No Quadro 1, no trecho que reescrevemos abaixo em (4a), notamos uma ocorrência da expressão tem vida [verbo + nome] em lugar de um verbo existencial ('houve', na nossa tradução), o que não ocorre no PB. Verificamos o mesmo fenômeno no nome vida, em (4b), produzido por outro informante da pesquisa, que traduzimos como "tem". Em Libras, a expressão tem vida ou o nome vida podem equivaler a um verbo existencial (ter, haver, existir).

(1) a. | tem vida surdo sala muito mais história |

'Houve, na sala de surdos, muito mais histórias.'

b. | vida interprete Libras estudar |

'Tem intérprete para estudo de Libras.' 
Em (4b), o constituinte vida parece ocupar a posição de um núcleo verbal ${ }^{15}$ que seleciona apenas um argumento interno ${ }^{16}$, o DP ${ }^{17}$ interprete, que recebe o papel de Tema. Os verbos existenciais se caracterizam por não selecionarem sujeitos $\operatorname{argumentais}^{18}$. É exatamente o que observamos na estrutura em (4a), considerando que o informante está realizando vida como um verbo. Como comenta Silva (2015), esses verbos são existenciais porque têm sentido de existência e selecionam um Tema como argumento. Tradicionalmente, esses verbos são conhecidos como impessoais.

Em (4a), entretanto, não temos uma estrutura típica de verbos existenciais, temos uma expressão existencial. Nesse exemplo, temos duas possibilidades de análise: ou temos uma estrutura argumental em que o núcleo verbal tem seleciona como argumento interno o DP vida, cujo papel temático recebido é o de Fonte, e como argumento externo ${ }^{19}$ o DP muito mais histórias, que recebe papel temático de Tema ${ }^{20}$; ou temos em tem+vida um item composto que faz as vezes do verbo existencial selecionando, nesse caso, o DP muito mais histórias como argumento interno com papel de Tema. Em outras palavras, em (4a), não observamos exatamente uma ocorrência de um nome em lugar de um verbo, mas a ocorrência de uma expressão que envolve verbo+nome em lugar de um verbo (houve), expressão que corresponde ipsis litteris à expressão em Libras de mesma estrutura e mesmo sentido, demonstrando claramente interferência da L1 na L2, conforme visualizamos a seguir, em exemplos da Libras,

\footnotetext{
${ }^{15}$ Categoria lexical que ocupa a posição de núcleo do sintagma verbal em Gramática Gerativa.

${ }^{16}$ Complemento de um núcleo lexical verbal, nominal, adjetival e adverbial em Gramática Gerativa.

17 Em Gramática Gerativa, DP é Sintagma Determinante, isto é, o sintagma cujo núcleo é o determinante do nome: o artigo, o demonstrativo, o possessivo etc. Para o DP interprete, pressupõe-se, por hipótese, um Determinante nulo.

${ }_{18}$ Em Gramática Gerativa, sujeitos argumentais são os que são selecionados como argumentos pelo verbo, recebendo deste um papel temático (ou semântico).

19 Um dos argumentos selecionados pelo núcleo predicador na estrutura argumental, tornando-se comumente o sujeito oracional.

${ }^{20}$ Essa estrutura temática pode parecer incomum, mas, se essa hipótese estiver correta, é justamente essa primeira concatenação do verbo + argumento interno Fonte que parece dar a essa expressão o caráter de um verbo existencial, que num segundo passo seleciona seu argumento externo como Tema do processo existencial.
} 
retirados de nosso corpus, em que nosso sujeito-informante 1, também em Libras, utilizou a expressão ter vida como verbo existencial.

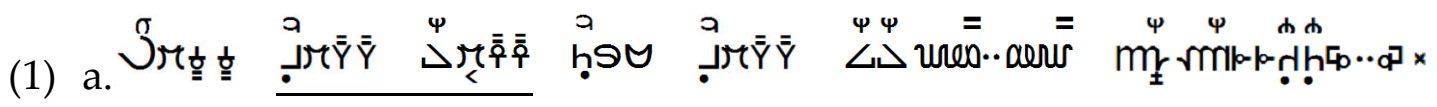
PORTUGUÊS T[er]-VIDA SURD[o/a] T[er] MUIT[o/a] SALA DE AULA

'Tem Português e têm muitos surdos na sala de aula.'

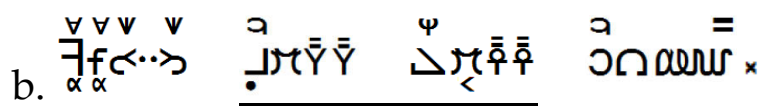

FAMÍLIA T[er] VIDA APREND[izagem]

'Na família, há aprendizagem.'

Também verificamos interferência da Libras no trecho do Quadro 1 reescrito abaixo em (6), no qual observamos que o item aviso ocorre como um nome selecionado como argumento interno do verbo falar, um tipo de seleção argumental que comumente não ocorre em Português.

(2) |Calma que fala aviso qualquer pode ajuda I

'Calma, que falo, informo e qualquer um pode ajudar.'

Em Libras, o sinal ....Mvv (AVISAR/INFORMAR) ocorre indistintamente como nome ou verbo, sem nenhuma alteração morfológica, como no exemplo (7a) a seguir, podendo, por isso, ocorrer em contextos sintáticos de nome ou verbo com menos restrições que em Português.

(3)

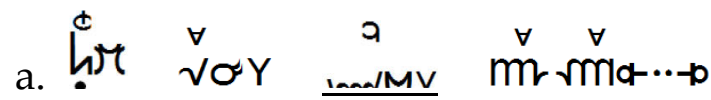

(4) $\times$ (Com função de nome) 
EU v[i] AVIS[o] (no) MURAL

'Eu vi o aviso no mural.'

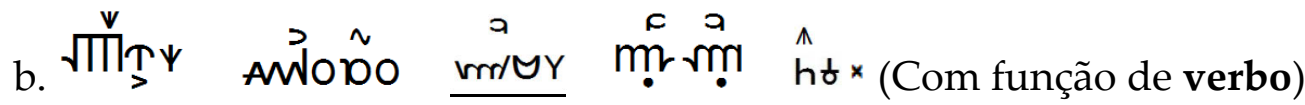
PASSADO J-O-Ã-O INFOM[ar] MOR[ar] AQUI

'João informou que mora aqui.'

Já no trecho do Quadro 1, reescrito em (8), encontramos três trocas que são exemplos de aspectos da L1 na L2, a saber: sentir saudade, estuda e escola.

(5) I futuro saudade legal não esnobar estuda quero escola |

'Sentirei saudade. É legal, não esnobo o estudo, quero estudar.

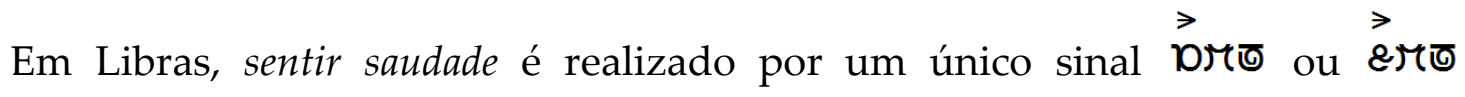
(SAUDADE). Ou seja, em Libras, apenas esse sinal dá conta do que, em Português, se expressa pelo verbo sentir subcategorizando ${ }^{21}$ o nome saudade. Conforme Almeida (2013), ocorre comumente em Libras um fenômeno de incorporação de argumento interno ou externo pelo predicador, que a autora denominou autossaturação ${ }^{22}$. E a autora inclui o sinal SAUDADE entre os que sofreriam esse fenômeno. Ou seja, pela análise dessa autora, esse único sinal, que é inclusive articulado como uma única unidade $\mathrm{MLMov}^{23}$, estaria incluindo a raiz verbal e o argumento interno. Acreditamos

\footnotetext{
${ }^{21}$ Em Gramática Gerativa, a subcategorização é a seleção de complemento por um núcleo predicador. 22 Termo proposto por Almeida (2013) para um fenômeno da Libras em que um único sinal, por exemplo $\forall \quad \forall$

$m_{\alpha} \underset{\alpha}{ } \operatorname{frll}_{\alpha}$, (ABRIR PORTA), parece corresponder ao verbo com um de seus argumentos incorporado. Como, pela Gramática Gerativa, o verbo, por ser um predicador, deve saturar-se através da seleção argumental, a autora compreende que sinais da Libras como esse já ocorrem autossaturados, uma vez que já trazem um de seus argumentos.

${ }_{23}$ Conforme estudo de Lessa-de-Oliveira (2012, 2019), a unidade MLMov (formada pelos macrossegmentos Mão+Locação+Movimento) é uma unidade articulatória do sinal que compõe o $3^{\text {o }}$
} 
que o fenômeno da autossaturação de fato pode existir em línguas como a Libras. Há, porém, no caso desse sinal, também a possibilidade de analisá-lo como um núcleo nominal em função predicativa, cujo verbo copulativo (ser) está nulo, algo comum em Libras e na interlíngua Português-Libras, como atesta Sandes-da-Silva (2016, p. 86). E

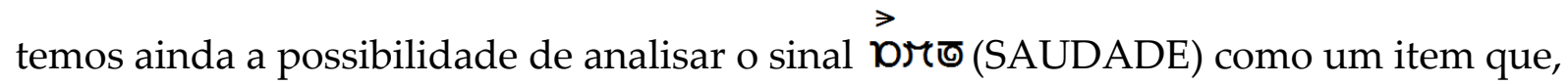
em Libras, ocupa também a posição de um verbo - saudadar. Todas essas possibilidades de análise podem ser consideradas tanto para exemplos da Libras, como (9a) e (9b) a seguir, como para a ocorrência do item saudade na interlíngua, em $(8)$.

(6)

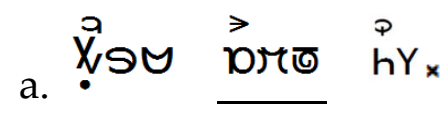

SURD[os] SENT[ir]-SAUDADE[s] VOCÊ

'Os surdos sentem saudade de você.' ou

'Os surdos estão com saudade de você'

b. LiY $\stackrel{P}{\text { DrT } \times}$

VOCÊ SENT[ir]-SAUDADE[s]

'De você, sinto saudade.'

(Adaptado de SANDES-DA-SILVA, 2016, p. 87)

Em relação à segunda troca, observamos que a ocorrência do item estuda em

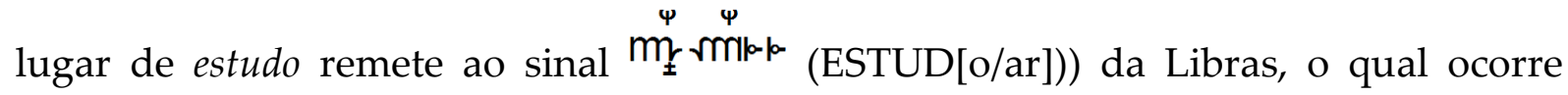
indistintamente com a mesma morfologia em posição nominal ou verbal. Já em relação à terceira troca, o nome escola em lugar do verbo estudar, verificamos uma relação

nível articulatório do sinal (correspondente ao nível das sílabas em Português), podendo o sinal ser formado por uma ou mais dessas unidades. 
muito direta com a estrutura morfossintática da L1. Em Libras, o nome escola se realiza

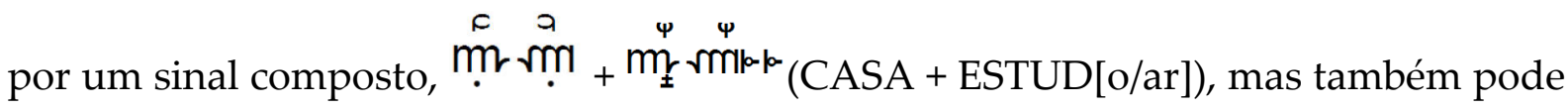

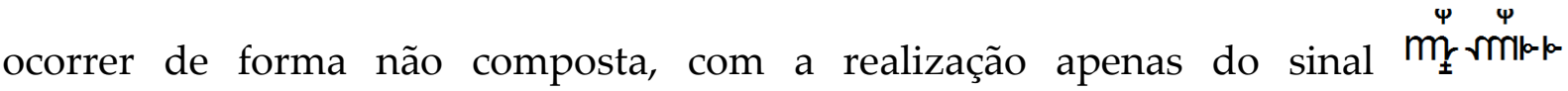
(ESTUD[o/ar]) (o segundo elemento do composto de escola). Assim, o que ocorreu, nesse caso, é que o informante trouxe para a interlíngua a indistinção entre as categorias nome e verbo da Libras, de forma a realizar o item nominal escola como o verbo estudar, semelhantemente ao que ocorre em Libras.

Por fim, vimos que, no trecho do Quadro 1, reescrito em (10h) abaixo, o item lexical errado, na forma de particípio, pode estar, em PB, em função adjetival ${ }^{24}$ - errado - ou verbal - errei.

(6) | desculpa culpa errado |

'Desculpe, foi minha culpa se estava errado' ou

'Desculpa, foi minha culpa se errei.'

Em Libras, essas duas possibilidades correspondem a uma única sentença, como em (11a). Em (11b), verificamos uma ocorrência do sinal $m_{\underline{\Psi}}^{\stackrel{\Psi}{\Psi} \underline{\underline{\Psi}} \underline{\underline{\Psi}} \underline{\underline{\Psi}}}$ (ERR[ar/ado]) em posição correspondente ao particípio em Português, em posição predicativa.

(7) a.

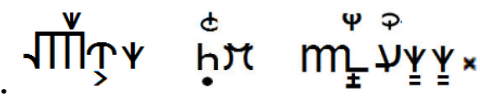

PASSADO EU ERR[ar/ado]

'Eu errei.' ou 'Eu estava errado.'

b.

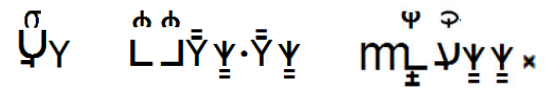

\footnotetext{
${ }^{24} \mathrm{Na}$ posição sintática de predicativo, o particípio é considerado um adjetivo e não um verbo.
} 


\section{S[eu] TRABALH[o] (está) ERR[ado] \\ 'O seu trabalho está errado'}

Os dados do Quadro 1, fornecidos pelo sujeito-informante 1, serviram aqui para demonstrar a análise qualitativa da ocorrência do fenômeno da troca categorial entre nomes e verbos que fizemos com os dados dos 11 sujeitos-informantes de nossa pesquisa. Entretanto, a restrição de espaço de um artigo nos impede de expor essa análise por completo. A seguir, passamos à análise quantitativa do fenômeno aqui investigado, agora referente aos dados dos 11 sujeitos-informantes, tratados, no gráfico a seguir, como SI1, SI2, SI3 e assim por diante.

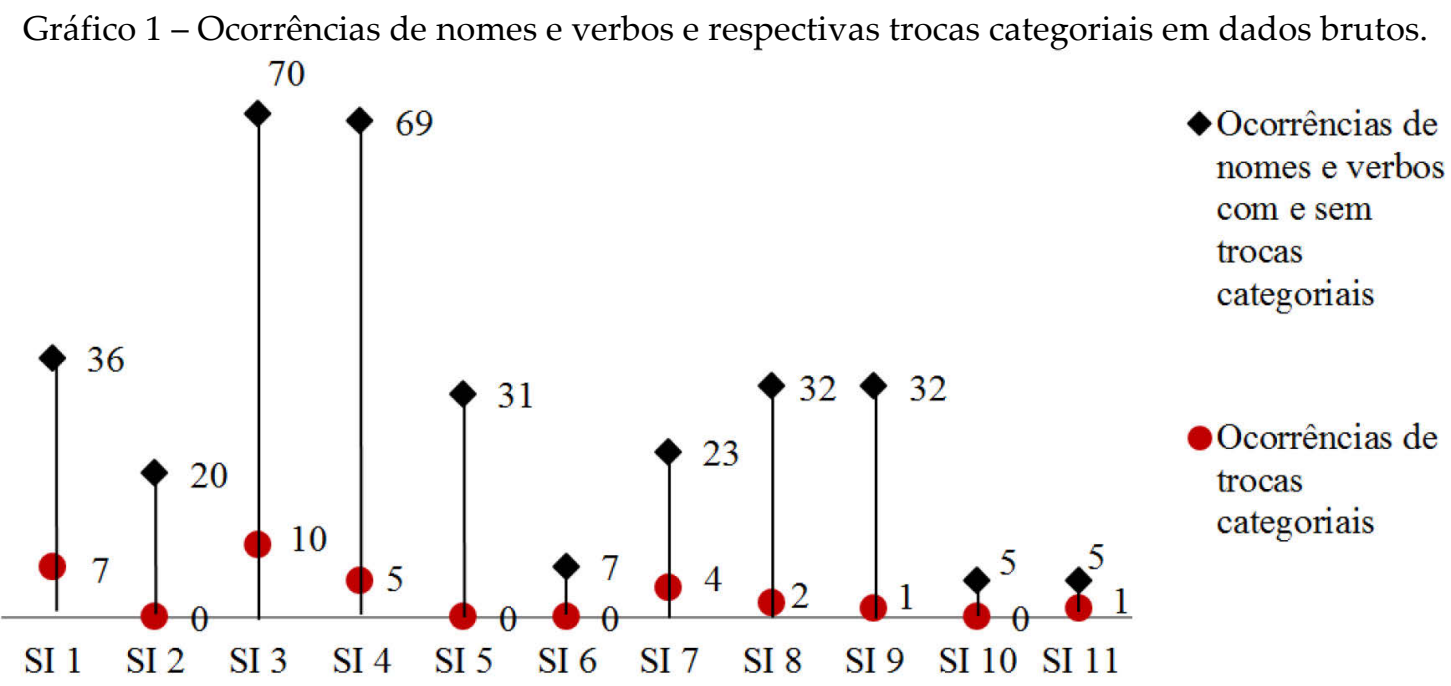

Fonte: Corpus da pesquisa

O gráfico acima compara dados brutos das ocorrências de trocas entre as categorias nome e verbo (círculos vermelhos) a dados brutos da distribuição de ocorrências de nomes e verbos no geral (losangos pretos) por informante. A partir desse gráfico, verificamos que SI3 e SI1 são os sujeitos-informantes que apresentam os maiores números de trocas categoriais, seguidos de SI4 e SI7. Entretanto, olhando para o índice percentual de trocas categoriais em relação à produção de cada informante, 
verificamos que proporcionalmente SI11 foi o que realizou o maior índice de trocas, 20 \% do que ele produziu, seguido por SI1 (19,44\%), SI7 (17,4 \%) e SI3 (14,3 \%), ficando os demais abaixo de $10 \%$.

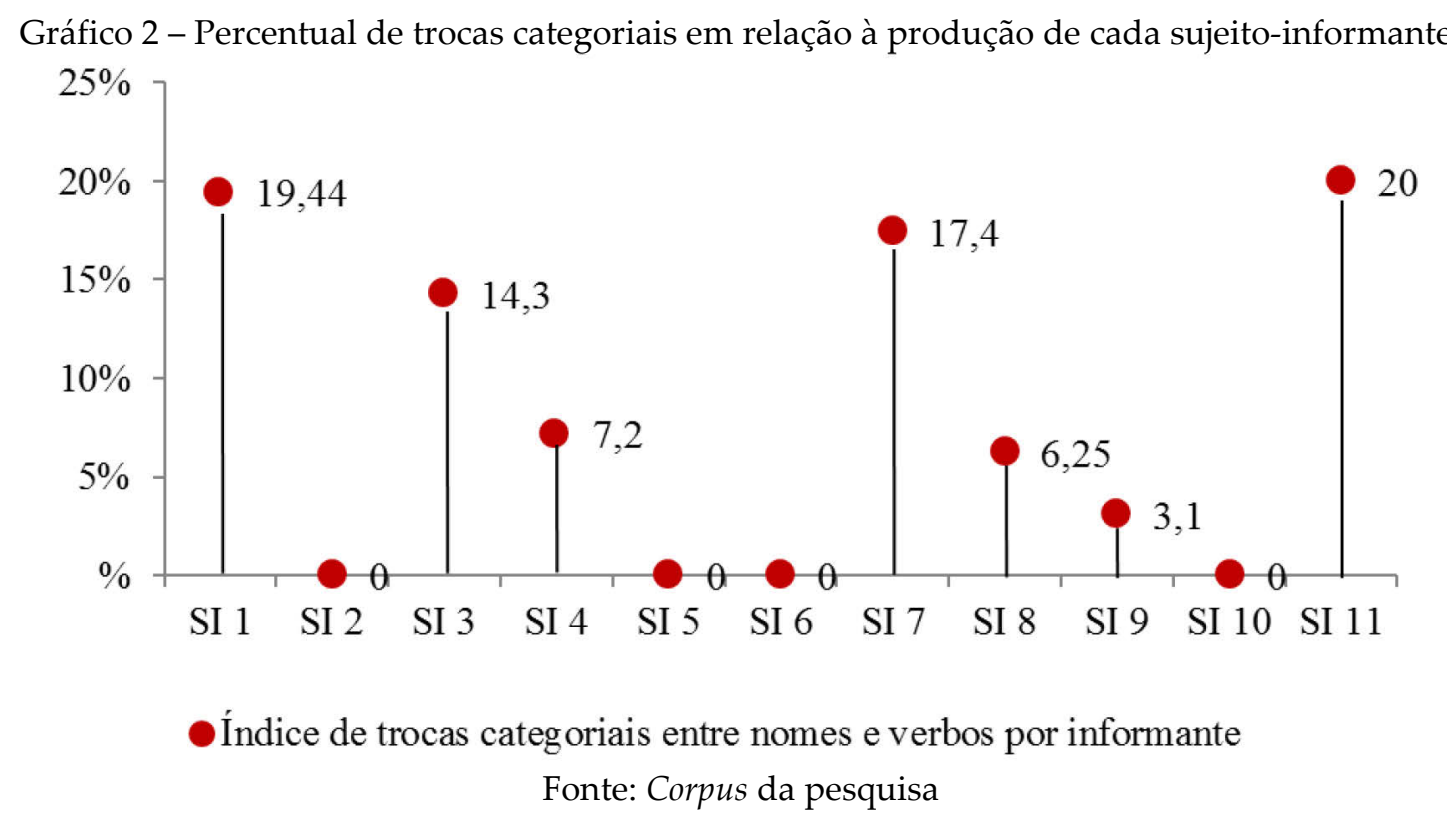

Vale salientar ainda que os sujeitos-informantes que ficaram com índices $0 \%$ de troca categorial estão entre os que realizaram menos nomes e verbos, isto é, não fizeram nenhuma troca, mas dois deles, SI6 e SI10, escreveram muito pouco, como se pode verificar no gráfico anterior. Ou seja, $0 \%$ de troca categorial nos dados desses dois informantes não significa que eles tenham já adquirido as marcas categoriais de nomes e verbos em Português, pelo contrário, a realização de textos muito curtos pode indicar maior dificuldade com a língua-alvo.

Já nos dados de SI2 e SI5, que também apresentam $0 \%$ de trocas, observamos um volume maior de ocorrências de nomes e verbos, tendo SI5 apresentado praticamente o mesmo volume de ocorrências de nomes e verbos (31 ocorrências) que os informantes SI8 e SI9 (32 ocorrências), havendo SI8 feito duas e SI9 feito uma troca. Então, esses sujeitos-informantes estão no mesmo estágio, ou seja, arriscam escrever um pouco mais, sem fazerem quase nenhuma troca de categoria. 
Por fim, vemos que o SI4, que se destaca pelo volume de verbos e nomes realizados (69 ocorrências) e um índice de trocas não muito alto $(7,2$ \%), é o sujeitoinformante que obteve melhor desempenho, pois, não obstante as trocas categoriais ainda realizadas, apresentou proporcionalmente produção mais próxima da línguaalvo. O segundo nesse ranking é SI3, que, embora apresente um índice mediano de trocas $(14,44 \%)$, realizou o maior volume de nomes e verbos (70 ocorrências). Em seguida, temos nesse ranking SI9, SI8, SI5 e SI2, que ficam em posição mediana.

Os resultados mostram também que o fenômeno de indistinção categorial é recorrente porque ele foi encontrado nos textos de 7 (sete) de nossos 11 (onze) sujeitosinformantes, isto é, nas produções escritas de 63,6 \% de nossos SIs. Todavia, é preciso admitir que se trata de um fenômeno de baixo volume de ocorrência, uma vez que o percentual individual de frequência média foi de apenas $9 \%$. Isto quer dizer que, em $91 \%$, em média, das ocorrências de verbos e nomes no corpus, não ocorreu troca de categoria, ainda que os morfemas flexionais não apresentem a concordância exigida quanto a todos os traços verbais ou nominais de determinados itens lexicais. Ressaltase aí o fato de que, mesmo entre os sete informantes que realizaram troca de categoria, houve esmagadora maioria de não troca categorial.

Em suma, o cenário quantitativo apresenta uma diversidade grande de nível de aquisição da morfologia própria das categorias nome e verbo em PB. Isso é esperado tanto em processo de aquisição de L2 como em processo de aquisição da escrita, que trazem como uma de suas características maiores diferenças individuais, conforme afirma Kato (2005). Excetuando-se os que apresentam uma produção muito tímida de escrita, os que despontam com certo grau de aquisição das categorias nome e verbo do PB apresentam o fenômeno da troca categorial com percentuais bem significativos, que chegam a $20 \%$.

Em todos os casos constatados nesta pesquisa, vemos o fenômeno explícito da troca categorial por indistinção morfofonológica. Como ocorre em Libras, esses itens 
têm a mesma estrutura, de acordo com os exemplos abaixo, (12a), (12b) e (12c), a seguir. Logo, por acesso indireto à GU, via gramática de sua língua materna, os informantes parecem estar transferindo essa indistinção da L1 para a escrita da L2, mais uma vez confirmando nossas hipóteses e configurando, consequentemente, uma interlíngua com características do PB e da Libras.

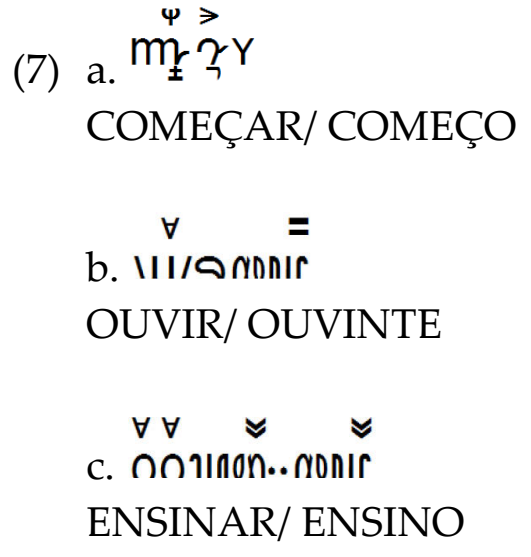

Os exemplos em (12) mostram o que vimos afirmando até aqui acerca da indistinção categorial na Libras, fato atestado pelas pesquisas de Pizzio (2011) e Lavras (2019). É nítido que a articulação do sinal na língua de sinais ocorre da mesma maneira tanto para o nome como para o verbo, representado por apenas um item lexical em SEL. Assim, o contexto discursivo, na maioria dos casos, será o responsável pela clareza do que se quer comunicar, ou mesmo pela criatividade intuitiva dos utentes de línguas naturais, como ficou comprovado na pesquisa de Pizzio (2011), na qual os sujeitos-informantes surdos utilizaram, no ato da comunicação, algumas estratégias para distinguir nomes de verbos.

Entretanto, os resultados apresentados aqui também indicam que esse processo de aquisição morfossintática das categorias nome e verbo, relativo à língua-alvo, está acontecendo, uma vez que verificamos nos dados um número significativo de convergência categorial com o PB, como percebemos nos exemplos abaixo, nos quais, como se pode verificar, não há nenhuma troca categorial entre nomes e verbos. 
(8)

a. |bom gosto | (SI1)

'É bom, eu gosto.'

b. I vou trabalha estudar sempre | (SI3)

'Vou trabalhar e estudar sempre'

c. IQuando era menor na roça gostava jogar bola.। (SI5)

'Quando era menor, na roça, eu gostava de jogar bola.'

d. I mais importante criança surdas aprender Libras | (SI8)

'É mais importante crianças surdas aprenderem Libras.'

Portanto, os dados analisados trazem evidência de que a troca categorial entre nomes e verbos, verificadas nas produções escritas de nossos sujeitos-informantes surdos adquirindo o Português escrito, são resultado da interferência de sua L1, a Libras, na L2, o Português escrito, confirmando as hipóteses deste estudo.

\section{Conclusão}

Neste trabalho, dissertamos sobre o fenômeno linguístico da troca categorial entre nomes e verbos cuja ocorrência foi identificada durante o processo de aquisição da escrita da interlíngua Português-Libras. Nossos objetivos principais foram os de descrever e analisar, com base nos dados de nosso corpus e à luz da Gramática Gerativa, o processo de aquisição tardia, por surdos, das categorias nome e verbo em Português Brasileiro escrito, com vistas a descrever como o fenômeno da troca categorial se realiza na produção escrita do surdo. Partimos, então, de três hipóteses: (a) a primeira, discutida por Kato (2005), diz respeito ao acesso indireto à Gramática Universal no processo de aquisição de uma segunda língua; (b) a segunda concerne à indistinção na escrita, em interlíngua Português-Libras, entre as categorias lexicais verbo e nome por interferência da mesma indistinção morfofonológica existente na Libras; e (c) a terceira diz respeito às estratégias utilizadas pelos adquirentes surdos, 
que os levam a se pautarem na natureza sintática da interlíngua, desprezando, na maioria dos casos, os aspectos morfológicos dessas duas categorias gramaticais do PB.

Na apresentação e discussão dos resultados, vimos que a ocorrência de nomes e verbos nos dados dos informantes variou um pouco quanto às quantidades. Ao todo, apareceram 173 nomes e 132 verbos em nosso corpus. Identificamos ausência da categoria verbal nos dados de um sujeito-informante e registramos apenas um verbo nos dados de outro informante, apesar de sabermos que nomes e verbos devem ser recorrentes, de maneira geral, nas sentenças da língua, porque são fundamentais nas línguas naturais. Dos 11 sujeitos-informantes pesquisados, sete realizaram a troca entre as categorias nome e verbo. Também houve casos de ambiguidade na interpretação de nomes e verbos, pois, em algumas situações, o item lexical utilizado tinha a mesma morfologia tanto para o nome como para a primeira pessoa verbal no singular (trabalho [verbo] e trabalho [nome]), típico do PB, restando-nos diferenciá-los com base no contexto semântico.

Observando o contexto linguístico em que ocorreram as trocas categoriais, obtivemos respostas que indicam que, na maioria dos casos, a troca aconteceu entre os pares de nomes e verbos, ou seja, entre os correlatos (trabalhar/trabalho; estudar/estudo; começar/começo; ouvir/ouvinte; sentir saudade/saudade; conversar/conversa; desenhar/ desenho; aprender/aprendizagem; ensinar/ensino). Entre esses correlatos, chamaram-nos a atenção dois itens, verificados no corpus, que correspondem a compostos em Libras: escola, formado por dois sinais simples (CASA + ESTUDAR), e o verbo existencial, formado pela expressão TER VIDA. Os informantes tomaram, na realização da troca categorial do item escola, o que corresponde a apenas uma parte do composto em Libras - estudar; e, no caso do verbo existencial, um informante realizou a expressão ter vida, e outro, apenas vida; ambas as realizações com correspondência exata ao que ocorre em Libras, embora tais realizações sejam completamente inusitadas para o Português, o que pode ser tomado como evidências da interferência da L1 na L2. 
Portanto, com base na análise dos dados, comprovamos nossas hipóteses acerca da indistinção morfológica que ocorre na interlíngua por interferência da língua materna, já que a aquisição da segunda língua se dá por acesso indireto à GU, e deixamos os caminhos abertos para outras pesquisas sobre a troca categorial na interlíngua Português-Libras. Acreditamos que o presente estudo traz contribuição à compreensão dos estágios da interlíngua apresentados pelos surdos no processo de aquisição do Português escrito. Contudo, evidenciamos a necessidade de avanço nos estudos sobre essa interlíngua e sobre a aquisição do Português escrito por surdos.

\section{Referências}

ALMEIDA, M. A. P. T. Aquisição da estrutura frasal na língua brasileira de sinais. 2013. 91 p. Dissertação (Mestrado em Linguística) - Universidade Estatual do Sudoeste da Bahia, Vitória da Conquista, 2013. DOI https://doi.org/10.21840/siic/154670

ANDRÉ, M. E. D. A. Etnografia da prática escolar. São Paulo: Papirus, 1995.

BASTOS, C. L.; CANDIOTTO, K. B. B. Filosofia da linguagem. Petrópolis: Vozes, 2007.

BROCHADO, S. M. D. A apropriação da escrita por crianças surdas. In: QUADROS, R. M. de (org.). Estudos surdos I. Petrópolis: Arara Azul, 2006. cap. 9.

CÂMARA JR., J. M. Estrutura da Língua Portuguesa. 44. ed. Rio de Janeiro: Vozes, 2011. Edição original: 1970.

CHAIBUE, K. Universais linguísticos aplicáveis às línguas de sinais: discussão sobre as categorias lexicais nome e verbo. 2013. 162 p. Dissertação (Mestrado em Estudos Linguísticos) - Faculdade de Letras, Universidade Federal de Goiás, Goiânia, 2013. DOI https://doi.org/10.21165/el.v48i1.2419

CHOMSKY, N. Linguística cartesiana: um capítulo da história do pensamento racionalista. Tradução de Francisco M. Guimarães. São Paulo: Vozes, 1972.

CHOMSKY, N. Novos horizontes nos estudos da linguagem e da mente. Tradução de Marco Antônio Sant'Anna. São Paulo: Unesp, 2005. 
CHOMSKY, N. Uma entrevista sobre o Minimalismo. In: BELLETTI, Adriana; RIZZI, Luigi (orgs.). Sobre natureza e linguagem. Tradução de Marylene Pinto Michael. São Paulo: Martins Fontes, 2006. p. 113-200.

CHOMSKY, N. Linguagem e mente. São Paulo: Unesp, 2009.

FELIPE, T. A. Os processos de formação de palavras na Libras. ETD - Educação Temática Digital, Campinas, v. 7, n. 2, p. 200-217, jun. 2006. DOI https://doi.org/10.20396/etd.v7i2.803

GATTI, B. A.; BARRETTO, E. S. de S. (coord.). Professores do Brasil: impasses e desafios. Brasília: Unesco, 2009.

KATO, M. A. Sintaxe e aquisição na Teoria de Princípios e Parâmetros. Letras de Hoje, Porto Alegre, v. 30, n. 04, 1995.

KATO, M. A. A gramática do letrado: questões para a teoria gramatical. In: MARQUES, M. A.; KOLLER, E.; TEIXEIRA, J.; LEMOS, S. A. (org.). Ciências da linguagem: trinta anos de investigação e ensino. Braga: CEHUM (U. do Minho), 131$145,2005$.

LAVRAS, E. A questão da categorização morfológica para nome e verbo na Libras. 2019. 106 p. Dissertação (Mestrado em Linguística). Universidade Estadual do Sudoeste da Bahia, Vitória da Conquista, 2019. DOI https://doi.org/10.5327/z1677606220181853

LESSA-DE-OLIVEIRA, A. S. C. Libras escrita: o desafio de representar uma língua tridimensional por um sistema de escrita linear. Revel, v. 10, n. 19, 2012.

LESSA-DE-OLIVEIRA, A. S. C. Escrita SEL - Sistema de Escrita para Língua de Sinais (Blog). DOI https://doi.org/10.22481/el.v17i2.5338 Disponível em: http://sellibras.blogspot.com.br/. Acesso em: 11 fev. 2019.

LIDDELL, S. Grammar, gesture and meaning in American Sign Language. Cambridge: Cambridge University Press, 2003.

MARCINIUK, R. M. B. A teoria da processabilidade e a aquisição de L2. ANALECTA. Guarapuava: Paraná, v. 8, n. 2, p. 11-27, 2007. 
MATTOS, A. M. de A. A hipótese da gramática universal e a aquisição de segunda língua. Revista de Estudos da Linguagem, v. 9, n. 2, p. 51-71, 2000. DOI https://doi.org/10.17851/2237-2083.9.2.51-71

McCLEARY, L.; VIOTTI, E. Transcrição de dados de uma língua sinalizada: um estudo piloto da transcrição de narrativas na língua de sinais brasileira (LSB). In: SALLES, H. M. M. L. (org.). Bilingüismo e surdez. Questões lingüísticas e educacionais. Brasília, DF: Editora da UnB, 2007. DOI https://doi.org/10.26512/2014.12.t.17554

PIZZIO, A. L. A tipologia linguística e a Língua de Sinais Brasileira: elementos que distinguem nomes de verbos. 2011. 237 p. Tese (Doutorado em Linguística) Universidade Federal de Santa Catarina, Santa Catarina, 2011. DOI https://doi.org/10.5327/z1806-3144201700030005

SALLES, H. M. M. L. et. al. Ensino de língua portuguesa para surdos: caminhos para a prática pedagógica. vol. 1. Brasília: Mec/Seesp, 2007.

SANDES-DA-SILVA, J. M. A categoria verbal na interlíngua Português-Libras: aquisição da modalidade escrita do Português por surdos. 2016. 132 p. Dissertação (Mestrado em Linguística) - Universidade Estatual do Sudoeste da Bahia, Vitória da Conquista, 2016. DOI https://doi.org/10.15687/rec.2016.v9i1.048061

SANTANA, A. P. Surdez e linguagem: aspectos e implicações neurolinguísticas. São Paulo: Plexus, 2007.

SPINASSÉ, K. P. As interferências da Língua Materna e o aprendizado do Alemão como Língua Estrangeira por crianças bilíngues. Pandaemonium germanicum. v. 10, 2006, 283-338. DOI https://doi.org/10.11606/1982-8837.pg.2006.74570 Disponível em: https://www.revistas.usp.br/pg/article/view/74570/78175. Acesso em: 18 abr. 2019.

SILVA, I. B. de O. A categoria dos verbos na Língua Brasileira de Sinais. 2015. 182 p. Dissertação (Mestrado em Linguística) - Universidade Estatual do Sudoeste da Bahia, Vitória da Conquista, 2015. DOI https://doi.org/10.21840/siic/154670

VILLALVA, A. Estrutura morfológica básica. In: MATEUS, M. H. M. et al. Gramática da Língua Portuguesa. Lisboa: Caminho, 2003. 